\title{
The simplified design method on bearing capacity of Cold-formed Thin-wall Steel Composite Floor
}

\author{
Yu Guan ${ }^{1, a^{*}, \text { Shengnan Song }}{ }^{2, b}$ and Ruicheng Wang ${ }^{3, c}$ \\ ${ }^{1}$ Chang'an University, Xi'an, China \\ ${ }^{2}$ Northwest International Tendering Co., Ltd, Xi'an, China \\ ${ }^{3}$ Chang'an University, Xi'an, China \\ aguanyu88927@126.com, bsongshengnan87@126.com, cwangrc83@163.com
}

Keywords: cold-formed thin-walled steel; composite floor; bearing capacity; simplified design method

Abstract. In the process of use, cold-formed thin-walled steel composite floor should undertake the upper floor vertical load, transfer wind load and seismic force to the shear wall, so that the composite floor must have good bearing capacity. However, using theoretical derivation to calculate the bearing capacity of composite floor is rather difficult. Based on the finite element analysis, the composite floor whole model can be simplified to a combination of T-section model and inverted L-section model. On the basis of verifying the correctness of simplified models, this paper puts forward a simplified design method on bearing capacity of cold-formed thin-wall steel composite floor, called whole section effective estimation method, which can be very convenient for the design of composite floor.

\section{Introduction}

Cold-formed thin-wall steel composite floor ${ }^{[1,2]}$ is composed of floor joist, rim track, web stiffener and floor panel, as shown in Figure 1. The floor joist generally adopts cold-formed steel single limb C beam or built-up beam and spacing is $400 \sim 600 \mathrm{~mm}$. The rim track generally adopts cold-formed steel single limb U beam. The floor panel adopts oriented-strand board (OSB) or cold-formed steel deck

topped with lightweight concrete. What's more, all components of the composite floor are connected through the self-tapping screw. The composite floor, on the one hand, as a vertical bearing system transfers dead load and live load to the wall, then passing through the wall to the foundation. At the same time, it connects each vertical bearing component into a whole and becomes horizontal bracing of vertical load bearing structure to increase the stability of the whole structure, so that the composite floor can better play its carrying capacity; On the other hand, the composite floor as a horizontal structure system transfers and distributes wind load and earthquake action to the wall.

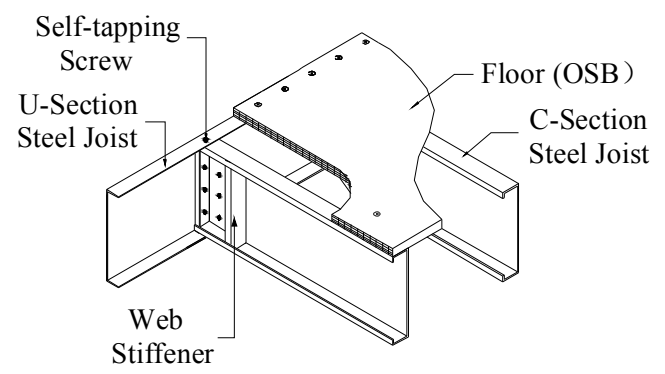

Figure 1. Cold-formed thin-wall steel composite floor.

Relatively few researches on simplified calculation model of cold-formed thin-wall steel composite floor were studied by domestic and foreign scholars ${ }^{[3,4]}$. This paper proposes that the composite floor whole model should be simplified as T-section model and inverted L-section model. Moreover, the simplified design method on bearing capacity of cold-formed thin-wall steel composite floor has been put forward, called whole section effective estimation method, which on the basis of verifying the correctness of the simplified model. 


\section{To establish and verify the simplified model}

To establish the simplified model. The composite floor whole model can be seen as the combination of T-section model and inverted L-section model, as shown in Figure 2. So the bearing capacity problem of composite floor can be transformed into the bearing capacity solving problem of T-section models and inverted L-section models, which greatly simplifies the solving process. Specific steps are as follows:

(1) Firstly, to decompose the composite floor model and establish a finite element model of $\mathrm{T}$-section and inverted L-section model;

(2) Secondly, to verify the correctness and feasibility of T-section and inverted L-section finite element model;

(3) Through the finite element analysis to prove the correctness and feasibility of the simplified design method.

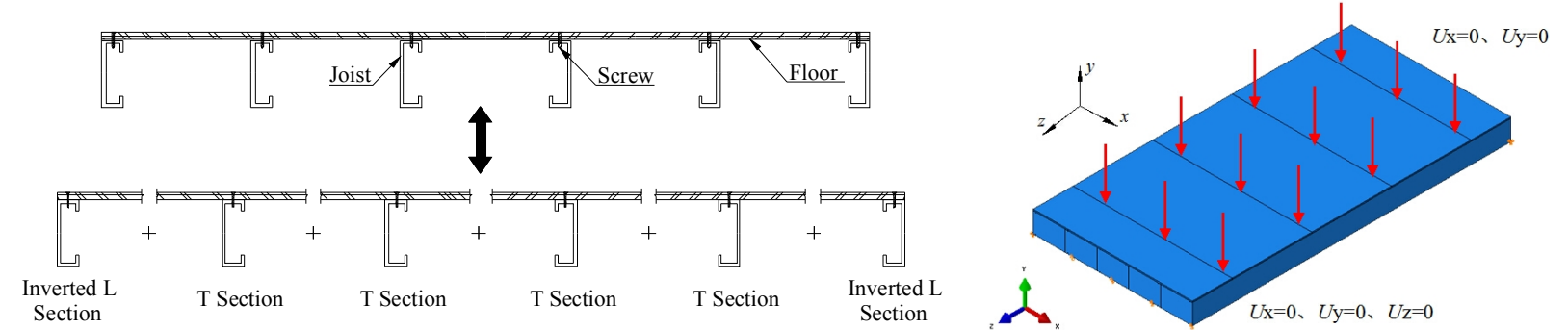

Figure 2. Combined section equivalent chart. Figure 3. The whole model of composite floor.

Abaqus finite element software was adopted to establish the whole model of composite floor, as shown in Figure 3, and T-section and inverted L-section simplified model, as shown in Figure 4. Simultaneously, to verify simplified finite element model with different parameters, as shown in Table 1. The floor joist spacing were $400 \mathrm{~mm}$ and $600 \mathrm{~mm}$, the section size of floor joist was $\mathrm{C} 305 \times 41 \times 14 \times 1.73$, the floor panel thickness was $18 \mathrm{~mm}$ and screw spacing was $150 \mathrm{~mm} / 150 \mathrm{~mm}$.

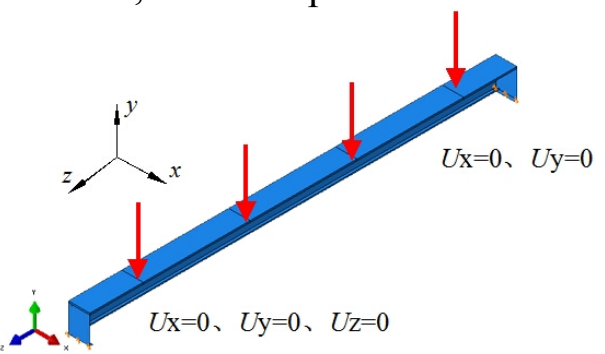

(a) inverted L-section simplified model

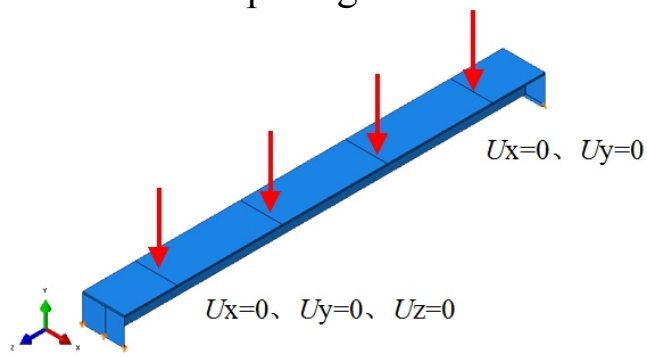

(b) T-section simplified model

Figure 4. The simplified model.

Table 1. The whole floor model parameters.

\begin{tabular}{|c|c|c|c|c|c|}
\hline \multirow{2}{*}{$\begin{array}{l}\text { Specimen } \\
\text { number }\end{array}$} & \multirow{2}{*}{ Joist type } & Joist spacing & $\begin{array}{c}\text { Floor size } \\
\text { length } \times \text { wide }\end{array}$ & $\begin{array}{c}\text { Floor panel } \\
\text { thickness }\end{array}$ & Screw spacing \\
\hline & & $\mathrm{mm}$ & $\mathrm{m} \times \mathrm{m}$ & $\mathrm{mm}$ & $\mathrm{mm}$ \\
\hline $\begin{array}{l}\text { C305-s400-1 } \\
\text { C305-s400-2 } \\
\text { C305-s400-3 }\end{array}$ & $\begin{array}{c}\text { C } 305 \times 41 \times 14 \times 1.73 \\
\text { U305 } \times 35 \times 1.73\end{array}$ & 400 & $\begin{array}{l}4.8 \times 2.0 \\
4.8 \times 2.4 \\
4.8 \times 2.8 \\
\end{array}$ & 18 & $150 / 150^{*}$ \\
\hline $\begin{array}{l}\text { C305-s600-1 } \\
\text { C305-s600-2 } \\
\text { C305-s600-3 }\end{array}$ & $\begin{array}{c}\text { C305 } 341 \times 14 \times 1.73 \\
\text { U305 } \times 35 \times 1.73\end{array}$ & 600 & $\begin{array}{l}4.8 \times 2.4 \\
4.8 \times 3.0 \\
4.8 \times 3.6 \\
\end{array}$ & 18 & $150 / 150^{*}$ \\
\hline
\end{tabular}

${ }^{*}$ In the table, the first 150 represents the surrounding screws connection spacing between the floor panel and joist is

$150 \mathrm{~mm}$, the second 150 represents the middle screws connection spacing between the floor panel and joist is $150 \mathrm{~mm}$.

To verify the simplified model. The joist, web stiffener and floor panel used the element Shell181 to simulate, the self-tapping screw connection of floor joists and floor panel used the beam element Beam1 88 to simulate. The constitutive relationship of steel adopts double broken line form. Steel used Von Mises yield criterion and isotropic hardening criterion, the yield strength was 
$334 \mathrm{MPa}$, the ultimate strength was $445 \mathrm{MPa}$, Poisson's ratio was 0.3 and elastic modulus was $2.06 \times 105 \mathrm{MPa}$. And oriented-strand board elastic modulus was $1910 \mathrm{MPa}$, the yield strength was 7.9MPa and Poisson's ratio was 0.11 . What's more, the finite element model considering local initial bending and overall initial bending of floor joist. Local geometric initial imperfection value was used local buckling mode of multi wave shape, meanwhile, overall initial bending referred to steel structure design code ${ }^{[5]}$ (GB50017-2003) was assumed to be half sine wave, and the peak value adopted 1/1000 of component length. The boundary conditions of the finite element model were simply supported by both sides and the applied load adopted the eight point loading mode to simulate uniform load. The finite element calculation results are shown in table 2.

Table 2. Comparison on the results of the whole model and the simplified models.

\begin{tabular}{|c|c|c|c|c|c|c|c|}
\hline \multirow{2}{*}{$\begin{array}{c}\text { Specimen } \\
\text { number }\end{array}$} & $\begin{array}{c}\text { T-section } \\
\text { model number }\end{array}$ & $\begin{array}{c}\text { inverted L-section } \\
\text { model number }\end{array}$ & $P_{\mathrm{uT}} *$ & $P_{\mathrm{uL}} *$ & $P_{\mathrm{uw}} *$ & $P_{\mathrm{u}} *$ & Error \\
\hline & $\mathrm{n}_{1}$ & $\mathrm{n}_{2}$ & $\mathrm{kN}$ & $\mathrm{kN}$ & $\mathrm{kN}$ & $\mathrm{kN}$ & $\%$ \\
\hline C305-s400-1 & 4 & 2 & & & 229.78 & 239.76 & 4.34 \\
\hline C305-s400-2 & 5 & 2 & 41.44 & 32.01 & 271.22 & 268.52 & 0.99 \\
\hline C305-s400-3 & 6 & 2 & & & 312.66 & 309.34 & 1.06 \\
\hline C305-s600-1 & 3 & 2 & & & 220.14 & 212.42 & 3.51 \\
\hline C305-s600-2 & 4 & 2 & 48.01 & 37.4 & 268.58 & 257.50 & 4.12 \\
\hline C305-s600-3 & 5 & 2 & & & 317.02 & 301.65 & 4.84 \\
\hline
\end{tabular}

From table 2 can be seen, the error of ultimate load between the whole model of composite floor and calculated by the simplified models are within 5\% range, which are in good agreement. It is proved that adopting simplified model to approximate simulate the whole model is feasible.

\section{The simplified design method}

In general, floor load is equivalent to uniformly distributed load. According to the distribution principle of floor load transferring to the nearest floor joist, the load sharing of inverted L-section model is only $50 \%$ of T-section model, while the yield load of inverted L-section model has reached 0.85 0.9 times of T-section model. Therefore, as long as the bearing capacity of T-section model can satisfy the design requirement, the bearing capacity of inverted L-section need not to be checked. Based on the feasibility of the simplified model, the composite floor bearing capacity problem can be converted to the T-section simplified model bearing capacity problem.

When the floor joist buckling, due to the influence of plate assembly effect, post-buckling related interaction and nonlinear factors, the post-buckling section stress distribution of floor joist is relatively complex and the effective width is not easy to determine, as well as using theoretical derivation to calculate the yield bending moment value of $\mathrm{T}$-section simplified model is rather difficult. Therefore, in order to calculate the yield strength of T-section model, which can be used whole cross section effective elastic limit bending moment of $\mathrm{C}$-section floor joist multiplied by combined effect influence coefficient $(\eta)$. As long as the bearing capacity calculated by this method is greater than the cross section bending moment design value of T-section model under external load, which namely that the composite floor bearing capacity satisfies the design requirements. This method is called whole section effective estimation method, and the calculation formula is:

$$
M_{\mathrm{y}}=\eta \cdot M_{\mathrm{cy}}=\eta \cdot W_{c} \cdot f_{y}
$$

where $M_{\mathrm{y}}=$ yield moment of T-section simplified model; $W_{\mathrm{c}}=$ the whole section effective bending resisting moment of single $\mathrm{C}$-section floor joist; $f_{\mathrm{y}}=$ steel yield strength. When used in engineering design, steel yield strength can be replaced with steel strength design value; $M_{\mathrm{cy}}=$ the elastic ultimate moment value of fully section effective bending of single C-section floor joist; $\eta=$ combined effect influence coefficient. Through the finite element parametric analysis and formula fitting, the simplified calculation formula of the combined effect influence coefficient can be calculated, as follows: 


$$
\eta=\alpha \cdot \beta \cdot\left(0.0168 h_{\mathrm{o}}+c\right)
$$

where $\alpha=$ floor joist spacing influence coefficient. When floor joist spacing is $400 \mathrm{~mm}, \alpha=1$. And when floor joist spacing is $600 \mathrm{~mm}, \alpha=1.09 ; \beta=$ screw spacing influence coefficient. When screw spacing is $150 \mathrm{~mm} / 150 \mathrm{~mm}, \beta=1$. And when screw spacing is $150 \mathrm{~mm} / 300 \mathrm{~mm}, \beta=0.85 ; h_{0}=$ the thickness of OSB floor panel( $\mathrm{mm}) ; c=$ floor joist web height influence coefficient, which approximate 0.9 .

\section{To verify the simplified design method}

In order to verify the correctness of the formula 1 and formula 2, selecting 12 different parameters of T-section simplified models for finite element analysis. And the parameters including screw spacing, floor joist spacing, floor joist web height, thickness of the joist, floor panel thickness and steel strength. The finite element calculation results and the results calculated by the whole section effective estimation method are shown in table 3.

Table 3. Comparison on the results of whole section effective estimation method and finite element analysis.

\begin{tabular}{|c|c|c|c|c|c|c|c|c|}
\hline $\begin{array}{c}\text { Screw } \\
\text { spacing }\end{array}$ & $\begin{array}{c}\text { floor joist } \\
\text { spacing }\end{array}$ & $\begin{array}{l}\text { floor joist } \\
\text { web height }\end{array}$ & $\begin{array}{c}\text { Joist } \\
\text { thickness }\end{array}$ & $\begin{array}{c}\text { floor panel } \\
\text { thickness }\end{array}$ & $\begin{array}{c}\text { Steel } \\
\text { strength }\end{array}$ & $M_{\mathrm{y}-\mathrm{EEM}^{*}}{ }^{*}$ & $M_{\mathrm{y}-\mathrm{FEA}}{ }^{*}$ & \multirow[t]{2}{*}{$M_{\mathrm{y}-\mathrm{EEN}} / M_{\mathrm{y}-\mathrm{FEA}}$} \\
\hline $\mathrm{mm}$ & $\mathrm{mm}$ & $\mathrm{mm}$ & $\mathrm{mm}$ & $\mathrm{mm}$ & $\mathrm{MPa}$ & $\mathrm{MPa}$ & $\mathrm{MPa}$ & \\
\hline \multirow{3}{*}{$150 / 150$} & \multirow{3}{*}{400} & 205 & 1.6 & 16 & 235 & 8.18 & 8.04 & 1.018 \\
\hline & & 255 & 1.6 & 14 & 235 & 10.52 & 11.06 & 0.950 \\
\hline & & 305 & 1.4 & 14 & 235 & 11.61 & 11.64 & 0.997 \\
\hline \multirow{3}{*}{$150 / 150$} & \multirow{3}{*}{600} & 205 & 1.6 & 16 & 345 & 12.65 & 13.15 & 0.962 \\
\hline & & 255 & 1.6 & 14 & 345 & 16.14 & 16.03 & 1.007 \\
\hline & & 305 & 1.4 & 14 & 345 & 17.63 & 17.42 & 1.012 \\
\hline \multirow{3}{*}{$300 / 150$} & \multirow{3}{*}{400} & 205 & 1.6 & 16 & 235 & 6.96 & 7.78 & 0.895 \\
\hline & & 255 & 1.6 & 14 & 235 & 8.94 & 9.86 & 0.906 \\
\hline & & 305 & 1.4 & 14 & 235 & 9.87 & 10.25 & 0.963 \\
\hline \multirow{3}{*}{$300 / 150$} & \multirow{3}{*}{600} & 205 & 1.6 & 16 & 345 & 10.75 & 11.66 & 0.922 \\
\hline & & 255 & 1.6 & 14 & 345 & 13.72 & 13.75 & 0.998 \\
\hline & & 305 & 1.4 & 14 & 345 & 14.98 & 14.86 & 1.009 \\
\hline
\end{tabular}

* In the table, $M_{\mathrm{y} \text {-EEM }}=$ the yield moment values obtained by whole section effective estimation method; $M_{\mathrm{y}-\mathrm{FEA}}=$ the yield moment values obtained by the finite element analysis.

From table 3 can be seen, the yield moment results calculated by the formula is very close to the finite element analysis results. So using the whole section effective estimation method to calculate the bearing capacity of cold-formed thin-wall steel composite floor is simple and feasible.

\section{Summary}

The composite floor whole model can be simplified to a combination of T-section model and inverted L-section model. On the basis of verifying the correctness of simplified models, this paper put forward a simplified design method on bearing capacity of cold-formed thin-wall steel composite floor, which called whole section effective estimation method. What's more, the simplified calculation formula of combined effect influence coefficient has been presented. Whole section effective estimation method is completely simple and avoids the solving process of the effective width method, which can be very convenient for the design of composite floor.

\section{References}

[1] Jia Ziwen, Zhou Xuhong, Liu Yongjian. Construction and design of cold-formed steel joists concrete composite floor. Building Structure. 43 (2013): 20 - 24.

[2] Zhou Xuhong, Shi Yu, Zhou Tian-hua, et al. Cold-formed steel framing system of low-rise residential building. Journal of Architecture and Civil Engineering: 22 (2005): 1-14.

[3] Wu Chuanwei. Theoretical and Experimental Research on Integral Bearing Behavior of Cold-formed Thin-wall Steel Composite Floor. Huaqiao university master's degree thesis, 2009. 
[4] Jia Ziwen. Study on the Behavior of Cold-Formed Steel Concrete Composite Floor. Chang' an university doctor's degree thesis, 2010.

[5] GB50017-2003. Code for design of steel structures. China planning press 